\title{
Caricature and face recognition
}

\author{
ROBERT MAURO \\ University of Oregon, Eugene, Oregon \\ and \\ MICHAEL KUBOVY \\ University of Virginia, Charlottesville, Virginia
}

\begin{abstract}
Although caricatures are often gross distortions of faces, they frequently appear to be superportraits capable of eliciting recognition better than veridical depictions. This may occur because faces are encoded as distinctive feature deviations from a prototype. The exaggeration of these deviations in a caricature may enhance recognition because it emphasizes the features of the face that are encoded. In two experiments, we tested the superportrait hypothesis and the encodingby-caricature hypothesis. In the first experiment, caricatures were recognized better than faces, and true caricatures of previously seen faces were recognized better than the faces from which the caricatures had been developed. In the second experiment, faces and their caricatures were tachistoscopically presented in a sequential same/different reaction time task. Subjects were slower to distinguish the stimuli when the face preceded its caricature, indicating that caricatures are more similar to the encoded representation of a face than are stimuli in which the distinctive features are deemphasized.
\end{abstract}

A caricature, like any portrait, is an attempt to portray something of the essence of a person (see Berger, 1952; Rother, 1966). However, in caricature, the artist is less bound by the constraints of reality. Facial features may be exaggerated beyond the possible, or even replaced by other forms. Yet when caricatures are successful, they seem to evoke recognition better than veridical portraits; they seem to be superportraits (see E. J. Gibson, 1969; Goldman \& Hagen, 1978; Perkins, 1975a, 1975b; Perkins \& Hagen, 1980). In the first experiment reported in this paper, we tested the hypothesis that caricatures may be better reminders of faces than are the original faces.

Caricatures remind the viewer of the identity of the subject through the use of symbolism or pictorial hyperbole. A symbolic caricature seeks to evoke the subject's identity through the depiction of something previously associated with the subject (see Gombrich, 1969). The subject's identity may be evoked by an item that is not part of the facial anatomy, such as Churchill's cigar, or by a distinctive feature of the face, such as Hitler's mustache. In these caricatures, the subject can only be recognized by viewers who share the artist's knowledge of the subject.

This research was supported by UPHS Grant MH-35137, a Rutgers University Research Council Grant, and a grant from the Rutgers University Johanna Busch Memorial Fund to the second author. We wish to thank the Identi-kit Co. (17985 Sky Park Circle, Suite C, Irvine, CA 92714) for lending us the Identi-kit and W. R. Garner for lending us his laboratory for the second experiment. Robert Crowder, Marc Sebrechts, and Jenny Alansky Mauro gave judicious advice for which we are grateful. Correspondence should be addressed to Robert Mauro, Department of Psychology, University of Oregon, Eugene, OR 97403-1227.
Few people are sufficiently well known to be effectively caricatured purely by symbolic caricature. Most caricatures utilize a form of pictorial hyperbole. In these portraits, distinctive facial features are replaced by exaggerations of those features. For example, Jimmy Carter's ubiquitous grin was often portrayed as a cavernous toothfringed smile. To construct this type of caricature, the artist must survey the features of the subject's face, determine which of these features are distinctive, and exaggerate these features in the portrait. In so doing, the caricaturist may mimic the process by which all faces are encoded and remembered.

Individuals may develop prototypes of faces as they appear to do of other natural forms (see Rosch, Mervis, Gray, Johnson, \& Boyes-Braem, 1976). Particular faces may be encoded as deviations from these prototypes (see E. J. Gibson, 1969; Solso \& McCarthy, 1981). Representations of faces in which the deviations from the prototypes are emphasized may be extraordinarily powerful cues for retrieving the identity of a face, because they emphasize the aspects of the face that are encoded and remembered.

There is some evidence that distinctive features are important for face recognition. ${ }^{1}$ Faces with unusual features are recognized better than more typical faces (Light, Kayra-Stuart, \& Hollander, 1979; Valentine \& Bruce, 1986), and when attention is focused on the distinctive features of a face, recognition for that face is enhanced (Winograd, 1981). However, it is not clear what constitutes a facial feature. A feature may be the shape of a particular facial component, such as the mouth, eyes, or nose (Ellis, Shephard, \& Davies, 1975; Friedman, Reed, \& Carterette, 1971; Matthews, 1978; McKelvie, 1976), or it 
may be a ratio between the gross lengths, widths, and proportions of the face (Harmon, 1973).

To construct a hyperbolic caricature of a face, the artist must exaggerate the face's distinctive features; that is, the artist must increase the deviation of those features from the prototype without changing the form of the initial deviation (Perkins, 1975a). For example, one individual's nose may be longer than the prototypical nose. To exaggerate this deviation, an artist would portray the nose as even longer. Another individual may have a nose that is more bulbous than the prototypical nose; the caricature of this face would have a nose that was even more bulbous. If the first individual's face were depicted with a bulbous nose, the resulting portrait would not be a caricature but a distortion, because the form of the deviation from the prototype was changed. In practice, caricaturists appear to show remarkable agreement on which features of a particular face to exaggerate and how they should be exaggerated (Goldman \& Hagen, 1978).

According to the superportrait hypothesis, by exaggerating the distinctive features of a face the caricaturist creates a representation that is more recognizable than a veridical portrait. There is some evidence for this idea. Rhodes, Brennan, and Carey (1987) demonstrated that computer-generated caricatures of individuals familiar to the experimental subjects were identified more quickly (but not more accurately) than veridical line drawings. However, other researchers using caricatures of unfamiliar faces (Hagen \& Perkins, 1983) or famous people (Tversky \& Baratz, 1985) produced by human artists have found that photographs are more recognizable than caricatures.

In trying to explain these discrepancies, Rhodes et al. (1987) suggest that caricatures may only be more recognizable than veridical drawings. Because photographs contain more information than drawings, faces portrayed in photographs may be more recognizable even though the features of the faces portrayed are less distinctive. However, Ryan and Schwartz (1956) and Fraisse and Elkin (1963) found that "caricatures" of common objects (simplified, cartoon-like drawings in which the characteristic features of the objects were emphasized) were recognized faster than veridical photographs.

Rhodes et al. (1987) also hypothesized that their results may have differed from those of other researchers because the memorial representation of a face may change with repeated exposures, becoming more similar to a caricature. Thus, caricatures may only be useful for accessing the memory of well-learned faces. However, Tversky and Baratz (1985) used caricatures of well-known people but failed to demonstrate the hypothesized superior recognizability of caricatures. They found that photographs of well-known people were more recognizable than caricatures.

There is another possibility. Despite admonitions to the contrary, the artists employed by Hagen and Perkins (1983) and Tversky and Baratz (1985) may have used symbolic caricaturing techniques in addition to exagger- ating the distinctive features of their subjects' faces. In practice, caricaturists use both symbols and pictorial hyperbole to evoke recognition, and they distort facial features to represent important aspects of a subject's past or personality as well as identity. When these techniques are used, a viewer's ability to recognize the person portrayed in a caricature depends on that viewer's knowledge of the depicted person.

Rhodes et al. (1987) may have succeeded in confirming the superportrait hypothesis where others failed, because the computer program used in their experiment exaggerated only the distinctive features of the faces to produce the caricatures. If so, caricatures in which only the distinctive features have been exaggerated should be more recognizable than the faces themselves, whether or not the persons depicted are familiar. In our first experiment, we tested the superportrait hypothesis by using unfamiliar Identi-kit faces and their caricatures.

\section{EXPERIMENT 1}

To avoid the problems inherent in caricatures constructed by human artists, we used an Identi-kit to construct both our stimulus faces and their caricatures. The faces were constructed to have only one feature that deviated from population norms. To construct an Identikit caricature of a face, we simply exaggerated the deviation of this feature from those norms.

The subjects were shown a learning series of slides of faces and caricatures, followed by a test series that included the previously seen faces and caricatures, new faces and caricatures, caricatures of the previously seen faces, and the faces from which the caricatures in the learning series had been developed. During the test series, the participants were asked to rate the certainty with which they believed that each stimulus had appeared in the learning series.

Memory operating characteristic (MOC) curves were fitted to each subject's rating-scale data for each of the face/caricature pairings: learn face-test face (FF), learn face-test caricature (FC), learn caricature-test face (CF), and learn caricature-test caricature (CC). Responses to new faces were used as noise in fitting the MOC curves for pairings in which faces were tested. Responses to new caricatures were used as noise in fitting the MOC curves for pairings in which caricatures were tested. ${ }^{2}$

Three sets of MOC curves were generated for each subject, one by using all of the data, the second by using the data from only those faces in which the manipulated feature was also perceived to be salient, and the third by using the data from only those faces in which the manipulated feature was not perceived to be salient.

Because the nonmanipulated features in the stimuli were allowed to vary randomly from face to face, features other than the manipulated feature may have been more salient. For example, a face with a slightly long nose may also have had large eyes. A true caricature would have portrayed this face with huge eyes as well as a longer nose. 
However, we were able only to make the nose longer. In so doing, we may have created a false caricature: a face similar to the first, but with an exaggerated feature that was not particularly salient in the original face. Though serendipitous, this mixture of stimuli allowed us to compare the recognizability of true and false caricatures.

To determine which caricatures were true caricatures, saliency rankings of the features in each of the faces were obtained. Ten subjects who did not participate in the memory experiment viewed the faces used in this experiment and rank ordered the three most salient characteristics of each face. The stimuli were then ordered according to the average rank of the exaggerated feature. Caricatures of 32 faces in which the exaggerated feature received a high saliency ranking (upper third of the saliency rank order) were considered to be true caricatures; caricatures of 31 faces in which the exaggerated feature was not considered one of the most salient or received a low saliency ranking (lower third of the saliency rank order) were considered to be false caricatures. Data from these faces and their caricatures (true caricature and false caricature data, respectively) were used to generate MOC curves.

Using these data, we tested three experimental hypotheses:

1. True caricatures of previously seen faces (FC) will be recognized better than old faces (FF), but false caricatures of old faces $\left(\mathrm{FC}^{\prime}\right)$ will not be recognized better than the previously seen faces $\left(\mathrm{FF}^{\prime}\right)$. If the superportrait hypothesis is correct, true caricatures will serve as better reminders of faces than the faces themselves because the faces' distinctive features are exaggerated in the caricatures. However, in false caricatures, the distinctive fea- tures are not exaggerated; the features that are exaggerated are not particularly salient in the original faces. Hence, false caricatures of old faces should not be recognized better than the previously seen faces.

2. Previously seen caricatures (CC)-whether true or false-will be recognized better than previously seen faces (FF). Because caricatures are unusual faces, they should attract more attention and be remembered better than other faces (Light et al., 1979).

3. Old caricatures (CC)-whether true or false-will be recognized better than the faces from which the previously seen caricatures were developed (CF). In this case, the distinctive features of the learned face (a caricature) are distorted toward the prototype in the test stimulus, instead of exaggerated.

\section{Method}

\section{Subjects}

Twenty-five undergraduate students ( 7 women and 18 men) participated in this experiment to partially fulfill a requirement for a course in introductory psychology. Data from 2 of these subjects (1 woman and 1 man) were eliminated from the analyses, because of problems with the experimental procedure.

\section{Materials}

Stimulus generation. Measures of the prototypical white male face were obtained from two anthropometric studies. Data on face and nose heights were obtained from Baer's (1956) study of nearly 6,000 caucasian male American military personnel, and data on chin height were obtained from Hooton and Dupertuis's (1951) study of approximately 10,000 Irish-American males.

Two hundred faces of caucasian males and caricatures of 150 of these faces were constructed with an Identi-kit. Three facial features were systematically varied in constructing these stimuli: (1) head height, (2) nose height, and (3) chin height (see Figure 1).

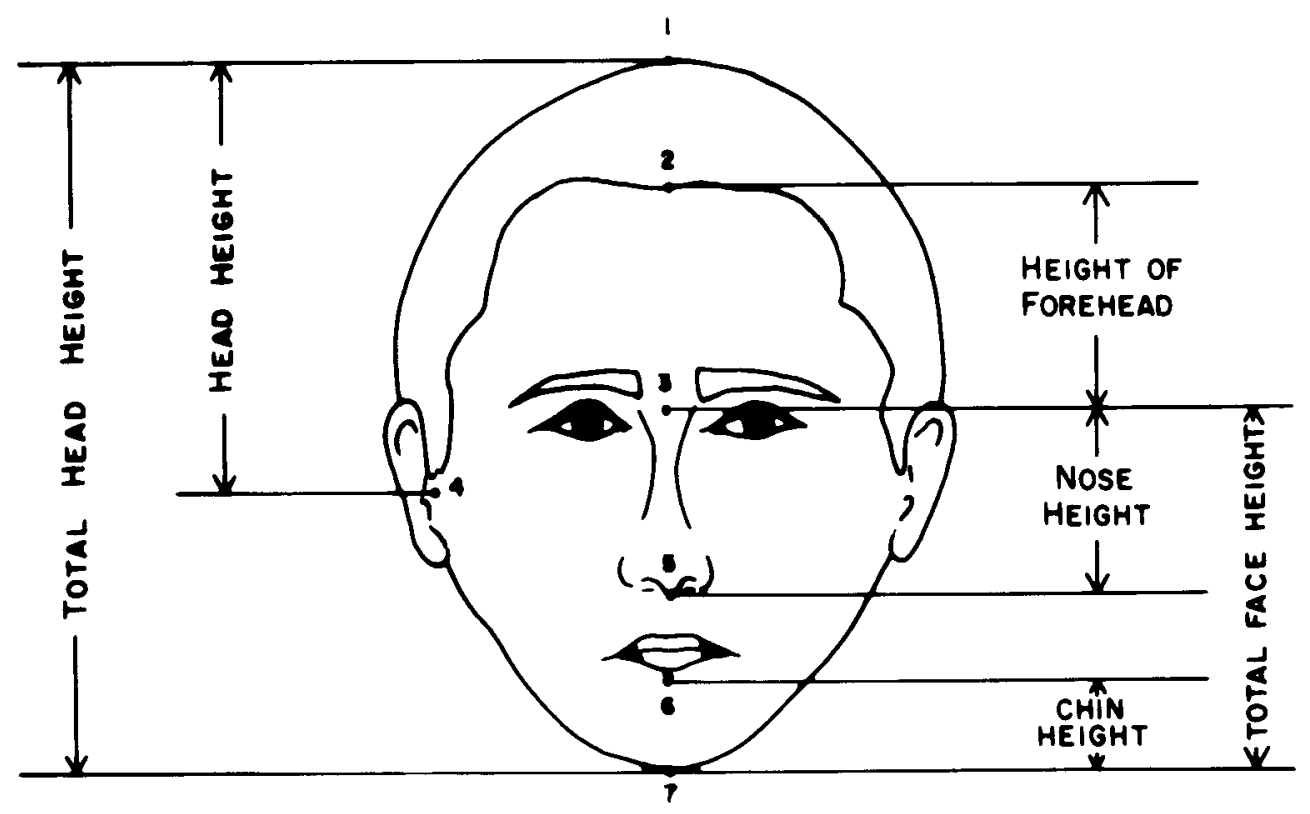

Figure 1. Facial features used in the construction of Identi-kit stimuli: (1) vertex, (2) trichion, (3) naison, (4) tragion, (5) subnasale, (6) labrale inferior, (7) gnathion. 

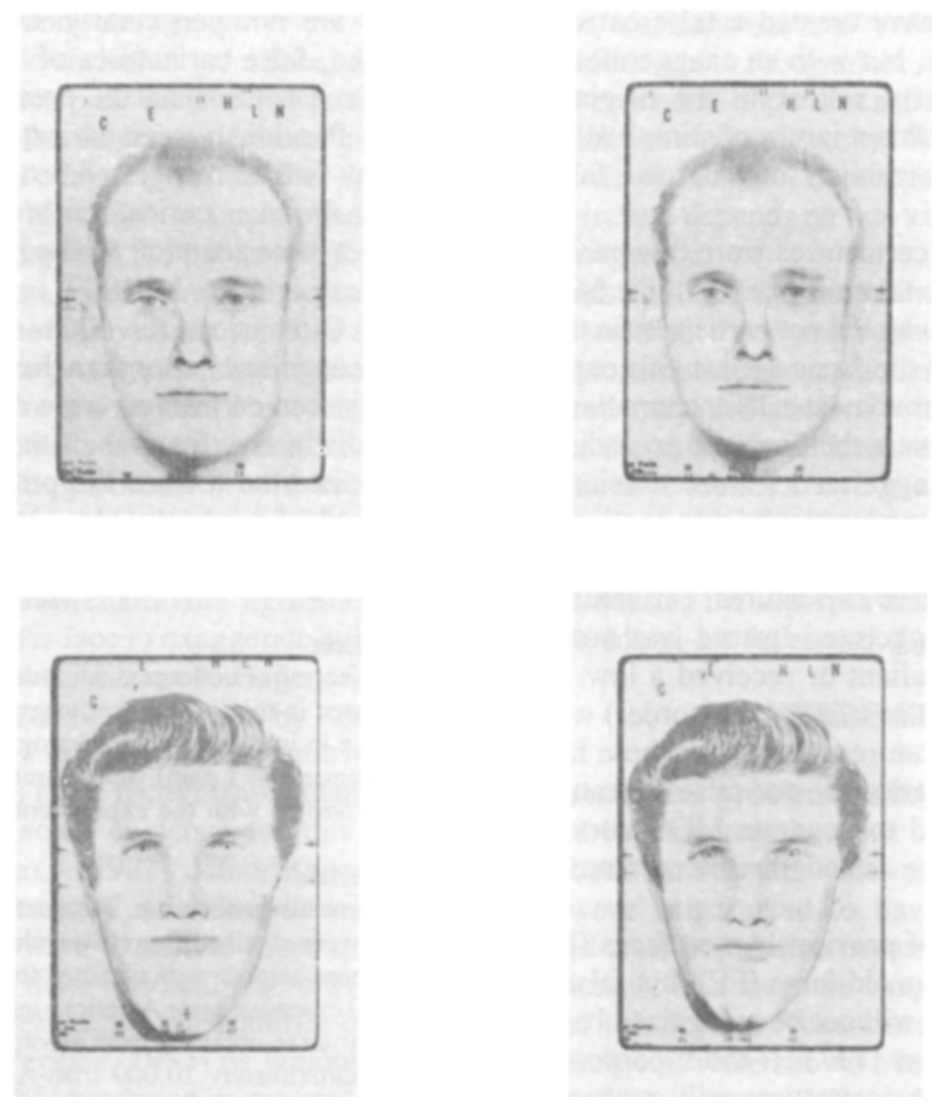

Figure 2. Two Identi-kit faces (right) and their caricatures (left): top, high forehead; bottom, long chin.

Six types of faces were constructed by making one of these features more than one standard deviation longer or shorter than average (long chin, short chin, high forehead, low forehead, long nose, short nose).

For each face, only one of these features was allowed to deviate from the population mean by more than one standard deviation. The other features of the faces were allowed to vary randomly from a subset of those available in the Identi-kit. The features in this subset were chosen to avoid obtrusive features (e.g., broken noses) that make faces easy to recognize (Patterson \& Baddeley, 1977; Yin, 1969). To form an Identi-kit caricature, we increased the deviation of the face's distinctive feature from the population mean. Long features were made longer; short features were made shorter (see Figure 2).

Composition of the stimulus sequences. One hundred slides were presented in the learning sequence: $\mathbf{5 0}$ randomly selected faces and the 50 noncorresponding caricatures. In the test sequence, 300 slides were presented: all of the faces and caricatures included in the learning sequence, 50 new faces, 50 new caricatures, 50 caricatures of faces seen previously, and $\mathbf{5 0}$ faces from which the previously seen caricanures had been developed. The order of the slides within each sequence was randomly determined for every other group run. The order of the slides for the intervening groups was the reverse of that for the preceding group.

\section{Procedure}

The subjects were instructed as follows:

\begin{abstract}
You are about to participate in a study of face recognition. You will first be shown a series of 100 slides. Each slide will be displayed for approximately 5 seconds.

After this sequence is completed, you will be shown 300 slides in a test sequence. While you are viewing each of the slides in this second group, we would like you to rate how certain you are that the face you are viewing is exactly the same or different from the one shown in the first series of slides. All of the slides in the first group will be included in the second group, along with 200 new slides.
\end{abstract}

These instructions were followed immediately by the presentation of the learning sequence. The test sequence was presented approximately $5 \mathrm{~min}$ after the completion of the learning sequence, following a brief amplification of the instructions specific to the response measure. The subjects were instructed to rate each slide in the test sequence on scales that ran from $1=$ certain it's new to $7=$ certain it's old. Each slide in the test sequence was displayed for $8 \mathrm{sec}$.

\section{Results}

Because the area under the MOC curve provides a more reliable estimate of sensitivity than $d^{\prime}$ when there are possible deviations from normality, we chose to base our analyses on the proportion of the total area under the MOC curves, $P(a)$. The arcsine transformations, 2[arc sine $\sqrt{P(a)}$ ], of these values were used as data in repeated 
measures analyses of variance. The transformed values are roughly linearly related to $d^{\prime}$ within the range obtained (McNicol, 1972).

For the MOC curves based on the data from all of the faces, only the main effect for the type of stimulus learned was significant $\left[F(1,22)=17.633, M S_{\mathrm{e}}=.005, p<\right.$ $.001]$. Subjects remembered caricatures better than faces (see Table 1) ${ }^{3}$ However, this analysis includes data from both true and false caricatures. When these data are analyzed separately, the predicted pattern is observed.

According to our first experimental hypothesis, true caricatures of previously seen faces will be recognized better than old faces, but false caricatures of old faces will not be recognized better than the previously seen faces (symbolically, FC $>$ FF $=\mathrm{FF}^{\prime}=\mathrm{FC}^{\prime}$ ). This pattern was observed [see Table $2 ; F(1,154)=4.173, p<.05$; omnibus $\left.F(3,154)=4.374, M S_{\mathrm{e}}=.027, p<.001\right]$.

Also as expected, caricatures were recognized better than faces $\left[F(1,154)=15.827, M S_{\mathrm{e}}=.027, p<.001\right]$, and old caricatures were recognized better than the faces from which these caricanures were developed $[F(1,154)=$ 6.736, $\left.M S_{\mathrm{e}}=.027, p<.05\right]{ }^{4}$

\section{Discussion}

As predicted by the superportrait hypothesis, depictions of faces in which the distinctive features were exaggerated were recognized better than the faces themselves. False caricatures were recognized better than faces, but only true caricatures served as better reminders of previously seen faces than the faces themselves.

These results corroborate the findings of Rhodes et al. (1987). However, those authors suggest that only caricatures of familiar faces would demonstrate this superior recognizability. According to Rhodes et al., as a face becomes more familiar, its representation in memory may become less veridical and more like a caricature. The results of our first experiment indicate that the superior recognizability of caricatures is not limited to familiar faces, but the results do not rule out the possibility that this superior recognizability is the result of a long-term memory mechanism-albeit one that requires only a single exposure to a face.

There is an alternative hypothesis: faces may be remembered as caricatures (that is, as exaggerated distinctive feature deviations from a prototype) because the distinctive features of the face are exaggerated during the initial encoding. According to this encoding-by-caricature hy-

Table 1

Recognizability of Faces and Caricatures: Mean Proportion of Area Under the MOC Curves, Based on All Data as a Function of Stimulus Learned and Stimulus Tested

\begin{tabular}{ccc}
\hline & \multicolumn{2}{c}{ Stimulus Tested } \\
\cline { 2 - 3 } Stimulus Learned & Face & Caricature \\
\hline Face & .602 & .618 \\
Caricature & .626 & .655 \\
\hline
\end{tabular}

Note-Larger values indicate greater recognition.
Table 2

Recognizability of Faces and Caricatures: Mean Proportion of Area Under MOC Curves for True and False Caricatures as a Function of Stimulus Learned and Stimulus Tested

\begin{tabular}{|c|c|c|}
\hline \multirow[b]{2}{*}{ Stimulus Learned } & \multicolumn{2}{|c|}{ Stimulus Tested } \\
\hline & Face & Caricature \\
\hline \multicolumn{3}{|c|}{ True Caricatures } \\
\hline $\begin{array}{l}\text { Face } \\
\text { Caricature }\end{array}$ & $\begin{array}{l}.601 \\
.593\end{array}$ & $\begin{array}{l}.641 \\
.662\end{array}$ \\
\hline \multicolumn{3}{|c|}{ False Caricatures } \\
\hline $\begin{array}{l}\text { Face } \\
\text { Caricature }\end{array}$ & $\begin{array}{l}.600 \\
.664\end{array}$ & $\begin{array}{l}611 \\
676\end{array}$ \\
\hline
\end{tabular}

Note-Larger values indicate greater recognition.

pothesis, there is no point in time at which the memorial representation of a face is veridical (see J. Gibson, 1966, 1973 , for relevant discussions). To determine whether or not the enhanced recognizability of caricatures is dependent on long-term storage, we conducted a second experiment in which the storage time was minimal.

\section{EXPERIMENT 2}

If faces are encoded as distinctive feature deviations from a prototype, one would expect that a stimulus in which the distinctive features of a face were emphasized would appear more similar to the encoded representation of a face than would a stimulus in which the distinctive features were deemphasized by the same amount.

Since caricatures are stimuli in which the distinctive features of a face are exaggerated, a face can be considered a stimulus in which the distinctive features of its corresponding caricature are deemphasized. Therefore, it should be harder to distinguish a test caricature from the encoded representation of the face on which it was based than it would be to distinguish a test face from the encoded representation of its corresponding caricature.

In Experiment 2, the subjects were shown pairs of slides in a sequential same/different reaction time task. Each pair included a face followed by itself, a caricature followed by itself, a face followed by its caricature, or a caricature followed by the face on which the caricature had been based. If a test caricature is more similar to the encoded representation of the corresponding face than a test face is to the encoded representation of its caricature, subjects should be slower to respond "different" to the facecaricature sequence than to the caricature-face sequence (see Podgorny \& Garner, 1979, for a discussion of reaction time as a similarity measure).

\section{Method}

\section{Subjects}

Twelve undergraduate college students ( 7 men and 5 women) who had not participated in the first experiment participated in the second experiment in partial fulfillment of the requirements of a course in introductory psychology. The data from 1 (female) subject were dropped from the study when she informed the experimenter that she had not understood the instructions. 


\section{Materials}

Twenty-eight pairs of faces and their corresponding caricatures were selected at random from the true caricatures used in Experiment 1 .

\section{Procedure}

The subject was seated $1.22 \mathrm{~m}$ from a translucent screen and was instructed to indicate (by flipping a toggle switch to the right or left) as quickly as possible without making errors whether the face in the second slide of each pair of slides was exactly the same as or different from the face in the first slide. The association between toggle direction and response was counterbalanced across subjects. The subjects were tested individually.

One hundred and twelve pairs of stimuli were presented. Each of the $\mathbf{2 8}$ face-caricature pairs was presented in each of the four possible sequences: a face followed by itself, a caricature followed by itself, a face followed by its caricature, and a caricature followed by its corresponding face. The stimulus order was randomized for each subject.

Each slide in a pair was presented for $500 \mathrm{msec}$, and there was a 500-msec interstimulus interval between slides in a pair. Reaction time was measured from the offset of the second stimulus (no subject responded while the second slide was being shown).

\section{Results}

The reaction times for each participant were converted into speeds (per second) and averaged over slides within each condition separately for correct and incorrect responses. Repeated measures analyses of covariance were performed on these data, using the arc-sine transform of the proportion of errors made as the covariate.

As predicted, subjects responded "different" faster to caricature-face pairs than to the face-caricature pairs $\left[F(1,29)=4.24, M S_{\mathrm{e}}=.589, p<.05\right.$; see Table 3]. If faster "different" responses are considered indicative of greater dissimilarity, these data imply that test caricatures are more similar to encoded faces than test faces are to encoded caricatures.

The participants were as fast to respond "same" to face-face pairs as to caricature-caricature pairs $\left[F(1,29)=.86, M S_{e}=.589\right.$, n.s. $]$. No significant differences between conditions in the speed of incorrect responses $\left[F(3,24)=2.30, M S_{\mathrm{e}}=5.32, \mathrm{n} . \mathrm{s}\right.$. $]$ or in the proportion of errors [after arc-sine transformation, $F(3,30)=$ $1.92, M S_{\mathrm{e}}=.100$, n.s.] were found. ${ }^{5}$

\section{GENERAL DISCUSSION}

In this study, we first sought to test the hypothesis that caricatures are extraordinarily recognizable portraits, more recognizable than the faces on which they are based. Results in accordance with this superportrait hypothesis were obtained in the first experiment. True (hyperbolic) caricatures of unfamiliar faces were recognized better than were the faces themselves.

In the second experiment, we sought to test whether the superior recognizability of caricatures was dependent on a long-term memory mechanism or whether it could be explained by an encoding process. We hypothesized that faces are encoded as exaggerated distinctive feature deviations from prototypes. Results in accordance with
Table 3

Mean Reaction Time (in Milliseconds) for Correct Responses by Referent Stimulus and Test Stimulus (With Proportion of Errors in Each Condition)

\begin{tabular}{lccccc}
\hline & \multicolumn{3}{c}{ Test } & & \multicolumn{2}{c}{ Caricature } \\
\cline { 2 - 3 } \cline { 5 - 6 } Referent & $M$ & P(Errors) & & $M$ & P(Errors) \\
\cline { 2 - 3 } \cline { 5 - 6 } Face & 152.07 & .12 & & 156.65 & .14 \\
Caricature & 139.95 & .20 & & 143.00 & .10 \\
\hline
\end{tabular}

Note-A "same" response was correct for the face-face and caricaturecaricature conditions; a "different" response was correct for the facecaricature and caricature-face conditions.

this encoding-by-caricature hypothesis were obtained in the second experiment. Subjects were slower to distinguish a test caricature from the encoded representation of the face on which it was based than they were to distinguish a test face from the encoded representation of its corresponding caricature. That is, a distortion of a face in which the distinctive features were exaggerated was harder to distinguish from the encoded representation of that face than was a distortion in which the distinctive features were deemphasized.

These results suggest that the encoded representation of a face is more similar to a caricature than to a distortion in which the distinctive features of the face are deemphasized by an equal amount. For this to occur, the distinctive features of the encoded representation of the face must be exaggerated. If the face were encoded veridically, a distortion of the face in which the distinctive features were deemphasized would be as similar to the encoded representation as a depiction of the face in which the distinctive features were emphasized by the same amount. In this case, the time needed to distinguish a test caricature from the encoded representation of the face on which it was based would not differ from that required to distinguish a test face from the encoded representation of its corresponding caricature.

These results confirm previous findings (Rhodes et al., 1987), and they support the widespread intuition that caricatures are extraordinarily recognizable portraits. However, contrary to previous suggestions (Rhodes et al., 1987), these results indicate that the extraordinary recognizability is not limited to caricatures of familiar faces or due to changes in the representation of faces in longterm memory.

Our results support the hypothesis that caricatures are powerful reminders of faces because they mimic the form in which faces are encoded. This process may not be limited to faces. It could explain the enhanced recognizability of "caricatures" of common objects reported by Ryan and Schwartz (1956) and Fraisse and Elkin (1963). That which determines what objects may be encoded by caricature is not clear. For example, Hyman and Frost (1975) observed that in classifying patterns of random dots, subjects appeared to consistently use a rule that stressed the exaggeration of differences between groups for some patterns but not for others. 
These results are also commensurate with the hypothesis that by exaggerating the distinctive features of a face, caricatures call attention to the features of a face that are critical to recognition. However, this idea by itself cannot explain the results reported here. If faces were encoded and stored in a more-or-less veridical form, caricatures could still provide better access to those memories than veridical faces, but once this access was obtained, it is not clear what would transpire.

For example, in the second experiment, when a face preceded its caricature, the caricature may have attracted subjects' attention to the distinctive features; the subjects may have recognized these features as having been present in the previously seen face and so may have found it difficult to distinguish the portraits. When a caricature preceded the corresponding face, the face may not have been as successful in attracting the subjects' attention to its distinctive features; the subjects may have failed to recognize the distinctive features of the previously seen caricature in the face and so may have found it easier to distinguish between these portraits.

However, this attentional mechanism would also predict the opposite result: when a face preceded its caricature, the caricature could have attracted the subjects' attention to the distinctive features; then the subjects could have noticed that the features were exaggerated in the caricature and so found it easy to distinguish between the portraits. For this mechanism to account for the results of the second experiment, not only must the caricature call attention to the distinctive features, but the encoded representation of the face also must not be easily distinguishable from a caricature. In effect, these results imply that either faces are encoded as caricatures or they are encoded in a form that is not easily distinguishable from a caricature.

The results of the second experiment could be explained by differences in the features on which the face and its caricature are compared. In a sequential same/different task, subjects may use the first stimulus as the referent with which they compare the second. They may then compare the second stimulus with the first by checking whether the relevant features in the first stimulus are present in the second. Hence, subjects may find it more difficult to detect additions to the first stimulus than deletions from the first stimulus (Agostinelli, Sherman, Fazio, \& Hearst, 1986). If the exaggeration of a feature acted like the addition of a feature, subjects might find it harder to detect differences in the face-caricature sequence than in the caricature-face sequence.

However, it is not clear that the exaggeration of a feature is equivalent to the addition of a feature. When exaggerated, the feature is present but distorted. If subjects are checking for the presence of this feature, they might be expected to notice the distortion. Furthermore, this mechanism cannot explain the results of the first experiment, in which caricatures of previously seen faces were recognized better than those faces were recognized. This mechanism by itself cannot explain why a changed stimulus should be more recognizable than an original stimulus. This is true even if the critical dimensions were those of the second stimulus instead of the first.

Of course, further research using more elaborate caricatures is needed to confirm these findings and test the hypothesized alternative mechanisms. Some of these tests could be relatively straightforward. For example, the attentional mechanism explanation of the superportrait effect implies that caricatures are not uniquely powerful representations. Portraits could be constructed in which means other than exaggeration (e.g., altering color or brightness) were used to call attention to the distinctive features of the faces. According to the attentional explanation, these portraits should be as effective as caricatures in enhancing recognition.

The encoding-by-caricature hypothesis has important implications for face recognition research. For example, if faces are encoded as distinctive feature deviations from prototypes, the search for the features that are critical for face recognition cannot succeed; the critical features will differ from face to face.

The results reported here also have implications for everyday face recognition. For example, unusual faces should be easier to remember and recognize than "ordinary faces." Faces with features that depart only slightly from prototypes are the kind of faces that make caricaturists despair. These faces may be not only difficult to caricature, but difficult to encode. People with ordinary faces are said to make good spies, because one can look right at them and never notice their presence.

The results of our experiments also imply that most physical manipulations (e.g., unusual hair styles, colors, lipsticks) that call attention to people's faces when they are first met may (like a false caricature) increase the likelihood that the face will be remembered and later recognized. However, very few changes in appearance can increase the likelihood that an already known face will be recognized (like a true caricature). Most physical manipulations of one's appearance will not produce a true caricature.

The encoding-by-caricature hypothesis also may explain cross-racial decrements in face recognition (e.g., Cross, Cross, \& Daly, 1971; Malpass \& Kravitz, 1969). Individuals with little contact or need to identify members of another race may not develop race-specific prototype faces. If these faces are encoded in relation to existing prototypes, the salient "distinctive" features that are encoded may be characteristics (e.g., bone structure, hair texture) that distinguish racial groups, not the features that distinguish members of those groups. If these features are emphasized in the encoding process, the representations of these other-racial faces will become even more similar to each other. Caricatures have long been used to humor, entertain, agitate, and incite. Perhaps they can also help explain the successes and failures of human face recognition. 


\section{REFERENCES}

Agostinelu, G., Sherman, S., Fazio, R., Hearst, E. (1986). Detecting and identifying change: Additions versus deletions. Journal of Experimental Psychology: Human Perception \& Pefformance, 12, 445-454.

BAER, M. J. (1956). Dimensional changes in the human head and face in the third decade of life. American Journal of Anthropology, 14, 557-575.

Berger, O. (1952). My victims: How to caricature. New York: Harper

Cross, J. F., Cross, J., \& DAlY, J. (1971). Sex, race, age, and beauty as factors in recognition of faces. Perception \& Psychophysics, 10 , 393-396.

Ellis, H., Shepherd, J., \& Davies, G. (1975). An investigation of the use of the photo-fit technique for recalling faces. British Journal of Psychology, 66, 29-37.

Fraisse, P., * Elxin, E. (1963). Étude génétique de l'influence des modes de presentation sur le seuil de reconnaissance d'objets familiers. L'Année Psychologique, 63, 1-12.

Friedman, M. P., Reed, S.K., \& Carterette, E. C. (1971). Feature saliency and recognition memory for schematic faces. Perception \& Psychophysics, 10, 47-50.

GiBson, E. J. (1969). Principles of perceptual learning and development. New York: Meredith.

Gibson, J. J. (1966). The senses considered as perceptual systems. Boston: Houghton Mifflin.

Gibson, J. J. (1973). On the concept of 'formless invariants' in visual perception. Leonardo, 6, 43-45.

Goldman, M., * Hagen, M. (1978). The forms of caricature: Physiognomy and political bias. Studies in the Anthropology of Visual Communication, 5, 30-36.

Gомвrich, E. H. (1969). Art and illusion: A study in the psychology of pictorial representation. Princeton, NJ: Princeton University Press.

Hagen, M., Perkins, D. (1983). A refutation of the hypothesis of the superfidelity of caricatures relative to photographs. Perception, 12, 55-61.

HARMON, L. (1973). The recognition of faces. Scientific American, 229 (5), 70-84.

Hooton, E. A., DUPERTUIS, C. W. (1951). Studies in physical anthropology No. 2: Age changes and selective survival in Irish males. Ann Arbor, MI: American Association of Physical Anthropologists.

Hyman, R., Frost, N. H. (1975). Gradients and schema in pattern recognition. In P. Rabbitt \& S. Dornic (Eds.), Attention \& Performance $V$ (pp. 630-654). London: Academic Press.

Light, L., Kayra-Stuart, F., * Hollander, S. (1979). Recognition memory for typical and unusual faces. Journal of Experimental Psychology: Human Leaming \& Memory, 5, 212-228.

Malpass, R., Kravitz, J. (1969). Recognition for faces of own and other race. Journal of Personality \& Social Psychology, 13, 330-334.

MAtTheWs, M. L. (1978). Discrimination of ldentikit constructions of faces: Evidence for a dual processing strategy. Perception \& Psychophysics, 23, 153-161.

MCKELVIE, S. J. (1976). The role of eyes and mouth in the memory of a face. American Journal of Psychology, 89, 311-323.

McNicol, D. (1972). A primer of signal detection theory. London: Allen \& Unwin.

Patterson, K. E., a Baddeley, A. D. (1977). When face recognition fails. Journal of Experimental Psychology: Human Learning \& Memory, 3, 406-417.

Perkins, D. (1975a). Caricature and recognition. Studies in the Anthropology of Visual Communication, 2, 10-23.

Perkins, D. (1975b). A definition of caricature. Studies in the Anthropology of Visual Communication, 2, 1-10.
Perkins, D., Hagen, M. (1980). Convention, context, and caricature. In M. Hagen (Ed.), The perception of pictures: Vol. I. Alberti's window (pp. 55-61). New York: Academic Press.

Podgorny, P., \& GARNer, W. R. (1979). Reaction time as a measure of inter- and intraobject visual similarity: Letters of the alphabet. Perception \& Psychophysics, 26, 37-52.

Rhodes, G., BrenNaN, S., \& CAREY, S. (1987). Identification and ratings of caricatures: Implications for mental representations of faces. Cognitive Psychology, 19, 473-497.

Rosch, E., Mervis, C. B., Gray, W. D., Johnson, D. M., \& BoyesBraem, P. (1976). Basic objects in natural categories. Cognitive Psychology, 8, 382-439.

Rother, E. (1966). Drawing caricatures. Design, 67, 12-15.

Ryan, T. A., SChWARTz, C. B. (1956). Speed of perception as a function of mode of representation. American Joumal of Psychology, 69, 60-69.

Solso, R., McCarthy, J. (1981). Prototype formation of faces: A case of pseudo-memory. British Journal of Psychology, 72, 499-503.

Tversky, B,. \& Baratz, D. (1985). Memory for faces: Are caricatures better than photographs? Memory \& Cognition, 13, 45-49.

VALENTINE, T., BRUCE, V. (1986). The effects of distinctiveness in recognising and classifying faces. Perception, 15, 525-535.

WINOGRAD, E. (1981). Elaboration and distinctiveness in memory for faces. Journal of Experimental Psychology: Human Learning \& Memory, 7, 181-190.

Yn, R. K. (1969). Looking at upside-down faces. Joumal of Experimental Psychology, 81, 141-145

\section{NOTES}

1. By definition, the less similar a particular facial feature is to the corresponding features of other faces, the greater the distinctiveness of that feature.

2. The two noise distributions did not differ significantly $[t(22)=$ $1.68, p=.11$ ]. The mean certainty rating for the new faces was 3.16 $(S D=.48)$; the mean certainty rating for the new caricatures was 2.99 $(S D=.52)$.

3. The same pattern of results is observed if the mean certainty ratings (FF, 3.96; FC, 3.84; CF, 3.99; CC, 4.12) are analyzed [effect of stimulus learned $F(1,22)=7.42, M S_{\mathrm{e}}=.304, p=.012$ ]

4. The pattern of mean certainty ratings is similar but not identical to the pattern of means produced by the signal detection analyses (true caricatures: FF, 3.82; FC, 3.88; CF, 3.72; CC, 4.16; false caricatures: FF, 3.84; FC, 3.70; CF, 4.23; CC, 4.16). When these data are analyzed [omnibus $F(7,154)=3.647, M S_{e}=.280, p=.001$ ], only the $\mathrm{CC}=\mathrm{CC}^{\prime}>\mathrm{FF}=\mathrm{FF}^{\prime}$ comparison is significant $[F(1,154)=8.76$, $M S_{e}=.280, p<.011$.

5. An analysis of covariance was performed to ensure that the reported results were not the product of a speed-accuracy tradeoff. Although the proportion of errors made did not differ significantly between conditions, it was retained as a covariate, because nonsignificant differences in the proportion of errors can still affect the results of the analyses of interest. However, in this case, the pattern of results remains the same if the covariate is omitted. Two subjects did not make any incorrect responses in one of the categories; thus, the degrees of freedom for the denominator in the analysis of the speed of incorrect responses is correspondingly smaller.

(Manuscript received January 18, 1991; revision accepted for publication January $31,1992$. 